\title{
ARTICLE
}

Epidemiology

\section{Exogenous hormone use, reproductive factors and risk of intrahepatic cholangiocarcinoma among women: results from cohort studies in the Liver Cancer Pooling Project and the UK Biobank}

Jessica L. Petrick ${ }^{1,2}$, Úna C. McMenamin ${ }^{3}$, Xuehong Zhang ${ }^{4}$, Anne Zeleniuch-Jacquotte ${ }^{5,6}$, Jean Wactawski-Wende ${ }^{7}$, Tracey G. Simon ${ }^{8}$, Rashmi Sinha ${ }^{1}$, Howard D. Sesso, ${ }^{9,10}$, Catherine Schairer ${ }^{1}$, Lynn Rosenberg ${ }^{2}$, Thomas E. Rohan ${ }^{11}$, Kim Robien ${ }^{12}$, Mark P. Purdue ${ }^{1}$, Jenny N. Poynter ${ }^{13}$, Julie R. Palmer ${ }^{2}$, Yunxia Lu ${ }^{14}$, Martha S. Linet ${ }^{1}$, Linda M. Liao ${ }^{1}$, I-Min Lee, ${ }^{9},{ }^{10}$, Jill Koshiol' ${ }^{1}$, Cari M. Kitahara', Victoria A. Kirsh ${ }^{15}$, Jonathan N. Hofmann ${ }^{1}$, Barry I. Graubard', Edward Giovannucci ${ }^{9}$, J. Michael Gaziano ${ }^{10,16}$, Susan M. Gapstur ${ }^{17}$, Neal D. Freedman ${ }^{1}$, Andrea A. Florio ${ }^{1}$, Dawn Q. Chong ${ }^{18}$, Yu Chen ${ }^{5,19}$, Andrew T. Chan ${ }^{4,8,20}$, Julie E. Buring ${ }^{9,10}$, Laura E. Beane Freeman', Jennifer W. Bea ${ }^{21}$, Christopher R. Cardwell ${ }^{3}$, Peter T. Campbell ${ }^{17}$ and Katherine A. McGlynn ${ }^{1}$

BACKGROUND: Intrahepatic cholangiocarcinoma (ICC) arises from cholangiocytes in the intrahepatic bile duct and is the second most common type of liver cancer. Cholangiocytes express both oestrogen receptor- $\alpha$ and $-\beta$, and oestrogens positively modulate cholangiocyte proliferation. Studies in women and men have reported higher circulating oestradiol is associated with increased ICC risk, further supporting a hormonal aetiology. However, no observational studies have examined the associations between exogenous hormone use and reproductive factors, as proxies of endogenous hormone levels, and risk of ICC.

METHODS: We harmonised data from 1,107,498 women who enroled in 12 North American-based cohort studies (in the Liver Cancer Pooling Project, LCPP) and the UK Biobank between 1980-1998 and 2006-2010, respectively. Cox proportional hazards regression models were used to generate hazard ratios $(\mathrm{HR})$ and $95 \%$ confidence internals $(\mathrm{Cl})$. Then, meta-analytic techniques were used to combine the estimates from the LCPP ( $n=180$ cases) and the UK Biobank ( $n=57$ cases).

RESULTS: Hysterectomy was associated with a doubling of ICC risk (HR = 1.98, 95\% Cl: 1.27-3.09), compared to women aged 50-54 at natural menopause. Long-term oral contraceptive use $(9+$ years) was associated with a $62 \%$ increased ICC risk (HR= $1.62,95 \% \mathrm{Cl}: 1.03-2.55)$. There was no association between ICC risk and other exogenous hormone use or reproductive factors. CONCLUSIONS: This study suggests that hysterectomy and long-term oral contraceptive use may be associated with an increased ICC risk.

British Journal of Cancer (2020) 123:316-324; https://doi.org/10.1038/s41416-020-0835-5

\section{BACKGROUND}

Intrahepatic cholangiocarcinoma (ICC) rates have been rapidly increasing in the US since the mid-1980s. ${ }^{1}$ Between 2001 and 2016, ICC rates among US women more than doubled (from 0.6 to $1.4 / 100,000$ person-years, respectively). ${ }^{2}$ ICC arises from cholangiocytes in the intrahepatic bile duct and is the second most common type of liver cancer in the US, accounting for $12 \%$ of primary liver cancers. ${ }^{3}$

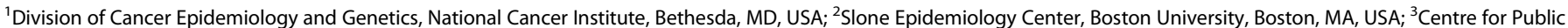

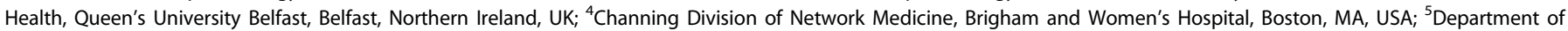

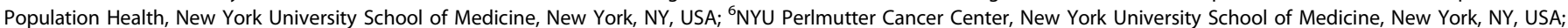

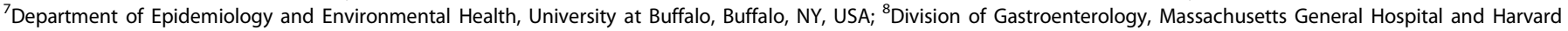

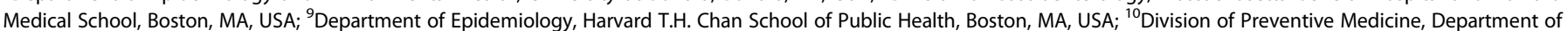

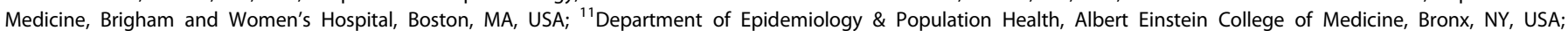

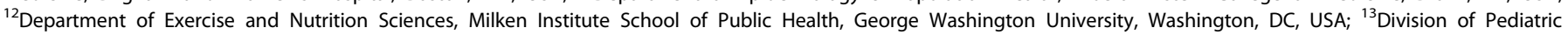

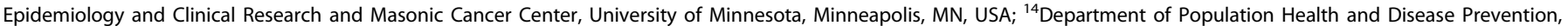

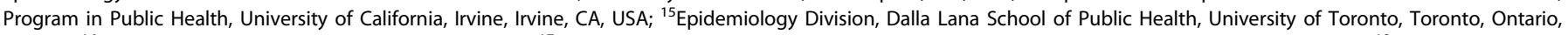

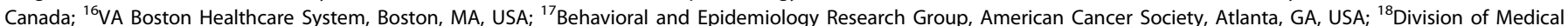

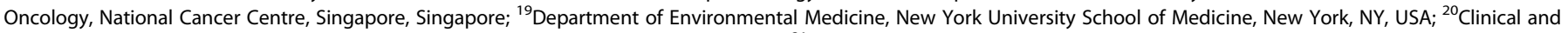
Translational Epidemiology Unit, Massachusetts General Hospital, Boston, MA, USA and ${ }^{21}$ Department of Medicine, University of Arizona, Tucson, AZ, USA

Correspondence: Jessica L. Petrick (jpetrick@bu.edu)

These authors contributed equally: Jessica L. Petrick, Úna C. McMenamin
}

Received: 10 September 2019 Revised: 5 March 2020 Accepted: 24 March 2020

Published online: 7 May 2020 
As cholangiocytes express both oestrogen receptor- $a$ and $-\beta^{4-6}$ hormonal factors have been hypothesised to play a role in cholangiocarcinogenesis. ${ }^{7}$ Experimental evidence suggests that oestrogen promotes cholangiocarcinogenesis, while selective oestrogen receptor modulators can inhibit growth. ${ }^{8-10}$ Additionally, a prior study from Khon Kaen, Thailand, reported higher circulating oestradiol in men with cholangiocarcinoma compared to controls. ${ }^{11}$ Another recent study from the Liver Cancer Pooling Project (LCPP) reported that higher levels of circulating oestradiol in women were associated with an increased ICC risk. ${ }^{12}$ Taken together, these results suggest that factors that affect oestrogenic regulation may play a role in the aetiology of ICC.

Several epidemiologic studies have examined exogenous hormone use and reproductive factors in relation to all primary liver cancer or hepatocellular carcinoma (HCC) risk, ${ }^{7,13}$ but not ICC risk alone. One recent study from Sweden found that menopausal hormone therapy (MHT) use was associated with a lower risk of gastrointestinal cancers, but there were too few cases to examine the association with ICC as a unique outcome. ${ }^{14}$ Thus, we conducted a prospective analysis of North American and European women to examine exogenous hormonal exposures and reproductive factors, as proxies of endogenous hormonal exposures, in relation to ICC risk.

\section{METHODS}

Study population

For this study, we combined the resources of the National Cancer Institute (NCl) Cohort Consortium and the UK Biobank. All North American-based cohort studies that are members of the $\mathrm{NCl}$ Cohort Consortium were invited to participate in the LCPP, as previously described. ${ }^{13}$ For the current study, which is restricted to women, 12 cohorts contributed information on exogenous hormones and/or reproductive factors and ICC cases: NIH-AARP Diet and Health Study (AARP), ${ }^{15}$ Agricultural Health Study (AHS), ${ }^{16}$ The Breast Cancer Detection Demonstration Project (BCDDP), ${ }^{17}$ Prostate, Lung, Colorectal and Ovarian Cancer Screening Trial (PLCO), ${ }^{18}$ Women's Health Study (WHS) ${ }^{19}$ New York University Women's Health Study (NYUWHS), ${ }^{20}$ Cancer Prevention Study-II (CPS-II) Nutrition Cohort, ${ }^{21}$ lowa Women's Health Study (IWHS), ${ }^{22}$ Black Women's Health Study (BWHS), ${ }^{23}$ Women's Health Initiative $(\mathrm{WHI}),{ }^{24}$ Nurses' Health Study (NHS), ${ }^{25}$ and the Canadian Study of Diet, Lifestyle, and Health (CSLDH) ${ }^{26}$ (Supporting Table S1). The Physicians' Health Study (PHS ${ }^{27}$ and Health Professionals FollowUp Study (HPFS) ${ }^{28}$ were excluded, as these cohorts only included men. The US Radiologic Technologists (USRT) Study ${ }^{29}$ is also excluded, as this cohort had no women ICC cases. The UK Biobank is a large prospective cohort study that recruited over 500,000 men and women aged 40-69 years from one of 22 assessment centres located across England, Scotland and Wales between 2006 and $2010 .^{30}$ All studies participating in the LCPP contributed deidentified data following data sharing agreements between $\mathrm{NCl}$ and the cohort's academic institute; the UK Biobank was approved by the North West Multi-Centre Research Ethics Committee, and all participants provided written informed consent.

With the exception of the CSLDH, all other studies contributed the full cohort of individuals. For cost-efficiency, CSLDH was performed using a case-cohort design. Thus, from the entire cohort of women in CSLDH $(n=39,618)$ at baseline, an agestratified random sample was selected to create a sub-cohort of women $(n=3224)$, which are utilised in analyses to represent the full cohort. ${ }^{31}$ In total, 1,107,498 women participants were included: 851,157 women from the LCPP and 256,341 women from the UK Biobank.

\section{Outcomes}

Incident primary liver cancer (defined as International Classification of Diseases, 10th edition [ICD-10] diagnostic code C22) was ascertained by linkage to state-, provincial- or country-specific cancer registries or medical/pathology record review; dates of follow-up are given for each study in Supplemental Table S1. Cases of ICC were classified using the ICD-O-3 morphology codes 8032-8033, 8041, 8050, 8070-8071, 8140-8141, 8160, 8260, 8480, 8481,8490 and 8560 . The current study included 237 ICC cases (LCPP $n=180$ and UK Biobank $n=57$ ) and 1,107,261 non-cases.

\section{Exposures}

In the LCPP, reproductive factors were self-reported via hard copy questionnaire and included age at menarche, parity, age at first birth, age at natural menopause, oophorectomy, fertile duration (years between menarche and menopause), oral contraceptive use, duration of oral contraceptive use, MHT use, recency of MHT use (never, current, former), duration of MHT use, type of MHT use (none, oestrogen-only MHT, oestrogen-progesterone combination $\mathrm{MHT}$, other), and MHT route of administration (none, oral, nonoral). In the UK Biobank, the same exposures were assessed in a similar self-reported manner via touchscreen computerised and interviewer-administered questionnaires at baseline. The exception to similar exposure ascertainment is type of MHT, which was only asked of women who reported 'current' MHT use at baseline and was verified during a verbal interview with a UK Biobank nurse.

\section{Statistical analysis}

Cox proportional hazards regression models were used to estimate hazard ratios (HRs) and 95\% confidence intervals (Cls) for the associations between exogenous hormone use and reproductive factors and risk of ICC. To account for the casecohort design of CSLDH in the LCPP, all cases were weighted as one, and non-cases were weighted according to the inverse of their stratum-specific sampling fractions. All participants in the remaining cohorts were weighted as one using PROC SURVEYPHREG. ${ }^{32}$ Follow-up of the analytic cohort occurred from time of exposure ascertainment until an event (i.e., incident ICC) or rightcensoring (i.e., death, loss to follow-up, or last date of follow-up), whichever occurred first. The proportional hazards assumption was tested using an interaction between exogenous hormones or reproductive factors with log(time) in models that included confounders; no violations were observed $(p>0.05)$. The adjusted study-specific effect estimates from the LCPP and the UK Biobank were combined using fixed-effects meta-analytic models.

Based on existing literature, LCPP models contained the following potential confounders: ${ }^{33}$ age (continuous), alcohol consumption (g/day: none, $\leq 1.08,>1.08-3.58,>3.58-13.54$, $>13.54$ ), body mass index (BMl, $<25,25-29.9, \geq 30 \mathrm{~kg} / \mathrm{m}^{2}$ ), diabetes (yes, no), race (white, other), smoking (never, former, current), parent cohort study, and education (<high school, high school, some college/vocational, college, graduate degree). UK Biobank models contained age (continuous), alcohol consumption [never, former, current light/occasional ( $<16 \mathrm{~g} /$ day), current heavy $(\geq 16 \mathrm{~g} /$ day)], BMI $\left(<25,25-29.9, \geq 30 \mathrm{~kg} / \mathrm{m}^{2}\right)$, smoking (never, former, current), and education (<secondary school, secondary school, college, graduate degree). Models using UK Biobank data were not adjusted for race, as almost $95 \%$ of the cohort is white, nor diabetes, as only one ICC case had a type 2 diabetes diagnosis. In the UK Biobank, medical history of hepatitis B and C virus (HBV/ $\mathrm{HCV}$ ) and cirrhosis were examined as potential covariates, but they did not alter the estimates and are not included in the final models (data not shown). Models examining reproductive factors also contained menopausal status (pre-, post-menopausal), while models examining menopausal factors (i.e., age at menopause and MHT use) were restricted to post-menopausal women. A lag analysis, excluding the first two years of follow-up, was performed to account for potential pre-existing liver disease. Analyses were conducted using SAS version 9.4 (SAS Institute, Cary, NC) and STATA version 14 (StataCorp LP, College Station, TX). 
Nested case-control study of HBV/HCV

In the LCPP, 47 ICC cases that had a serum sample available were tested for determination of HBV and HCV serology status, in addition to 98 matched controls. To determine HBV status, hepatitis B surface antigen ( $\mathrm{HBsAg}$ ) was assayed using the Bio-Rad GS HBsAg 3.0 enzyme immunoassay (Bio-Rad Laboratories, Redmond, WA, USA). To determine HCV status, antibody to hepatitis $C$ virus (anti-HCV) was assessed using the Ortho HCV Version 3.0 ELISA test system (Ortho-Clinical Diagnostics, Inc., Raritan, NJ, USA).

\section{RESULTS}

Participants averaged 13.0 years of follow-up (maximum 30.4 years) in the LCPP and 5.5 years of follow-up (maximum 8.5 years) in the UK Biobank. Table 1 summarises women participant characteristics, which were similar between the LCPP and the UK Biobank. For example, the mean ages of non-cases were 57.7 and 56.1 and cases were 61.9 and 60.3 years, respectively. Among the non-cases, there was a similar prevalence of non-smokers (51.0 vs. $59.6 \%)$ and individuals with a $\mathrm{BMI} \geq 30 \mathrm{~kg} / \mathrm{m}^{2}$ (20.4 vs. $\left.23.9 \%\right)$ in the LCPP and the UK Biobank, respectively. However, the LCPP had more post-menopausal non-cases ( 83.0 vs. $59.6 \%)$. In both the LCPP and the UK Biobank, ICC cases were more likely to be postmenopausal, to be current or past smokers, and to have a BMI $\geq$ $30 \mathrm{~kg} / \mathrm{m}^{2}$

As shown in Table 2, there were null associations between age at menarche, parity, or age at first birth and risk of ICC. Similarly, there was a null association with ever use of oral contraceptives $(\mathrm{HR}=1.12,95 \% \mathrm{Cl}: 0.82-1.53)$. However, examining duration of oral contraceptive use, nine or more years of use was associated with $62 \%$ increased risk of ICC in the combined study population $(\mathrm{HR}=1.62,95 \% \mathrm{Cl}: 1.03-2.55)$, which was in the same direction in both LCPP (HR $=1.71,95 \% \mathrm{Cl}: 1.01-2.89)$ and UK Biobank cohorts $(\mathrm{HR}=1.38,95 \% \mathrm{Cl}: 0.56-3.39)$.

There was no association with age at natural menopause, but there was a 2 -fold increased risk of ICC associated with hysterectomy ( $\mathrm{HR}=1.98,95 \% \mathrm{Cl}: 1.27-3.09)$, compared to women aged $50-54$ at natural menopause, which was driven by the results from the LCPP ( $\mathrm{HR}=2.25,95 \% \mathrm{Cl}$ : 1.38-3.65; Table 3). Further adjustment in the LCPP for MHT use did not substantially affect the estimate $(\mathrm{HR}=2.15,95 \% \mathrm{Cl}$ : 1.31-3.52), although women with hysterectomy were more likely to report MHT use -especially oestrogen-only MHT (Supplemental Table S2). There was no association with total fertile duration. Examining MHT use, including recency, duration, or route of administration, revealed no associations with ICC risk. However, there was a possible indication of increased risk of ICC and oestrogen-only therapy in post-menopausal women ( $\mathrm{HR}=1.44,95 \% \mathrm{Cl}$ : 0.91-2.28).

Among the 47 ICC cases and 98 controls evaluated for HBV and HCV infections, one case (2.1\%) and no controls were positive for HBsAg. For anti-HCV, no cases and three controls (3.1\%) were positive. The viral results were not incorporated into the main analyses, as the results were only available for a small proportion of LCPP participants. In sensitivity analyses that dropped $\mathrm{HBsAg}$ $(+)$ and anti-HCV $(+)$ cases, the results did not differ from the analyses that included all cases (data not shown). Similarly, analyses that removed cases that developed in the first two years of follow-up were similar to those presented (data not shown).

\section{DISCUSSION}

In the present study, long-term oral contraceptive use was associated with a $62 \%$ increased ICC risk, and hysterectomy was associated with a doubling of risk. The other reproductive factors were not associated with risk of ICC.

This is the first study to date to examine exogenous hormone use, reproductive factors and ICC risk. Prior studies have been limited to examination of all primary liver cancer or HCC only, which is the dominant form of liver cancer and accounts for $75 \%$ of primary liver cancer cases. ${ }^{7}$ Thus, all prior examinations of exogenous hormone use and reproductive risk factors for liver cancer have been primarily driven by the aetiology of HCC. However, we discuss these prior results herein to highlight the similarities and differences in the aetiology of these two types of liver cancer. HCC is 2-3 times more common among men than women, ${ }^{34}$ while incidence rates of ICC are only $30 \%$ higher in men than in women. ${ }^{35}$ Reasons for reduced sex differences in ICC risk are unclear, but may be partially explained by oestrogenic factors increasing risk in women, as reported in the current study.

In 1999, the International Agency for Research on Cancer (IARC) concluded that there was sufficient evidence that oral contraceptives increased risk of liver cancer in the absence of viral infections. ${ }^{36}$ However, a meta-analysis reported a $55 \%$ increased risk of liver cancer only in case-control studies, but no association in cohort studies. ${ }^{37}$ The most recent 2018 IARC monograph concluded that there was still sufficient evidence that oestrogenprogesterone combination oral contraceptives cause liver cancer. ${ }^{38}$ While the recent IARC monograph acknowledged that there was no association found in cohort studies, the majority of these to-date have included small numbers of cases. The prior study of HCC in the LCPP showed an increased, but non-significant, risk of HCC with more than 6 years of oral contraceptive use, ${ }^{39}$ which is similar to the significant increased risk of ICC reported herein for nine or more years of oral contraceptive use.

The reported associations between MHT use and primary liver cancer risk have been inconsistent. A recent meta-analysis reported that MHT was associated with a $40 \%$ decreased risk of primary liver cancer across five studies. ${ }^{40}$ Inverse associations were also reported for oestrogen-only, as well as oestrogenprogesterone combination MHT. However, there was significant heterogeneity between the studies in the meta-analysis. One of these studies examined MHT from prescription records and reported a $42 \%$ decreased risk of liver cancer. ${ }^{41}$ However, none of these studies were able to examine ICC independent of primary liver cancer. Our study reported that oestrogen-only MHT use in post-menopausal women was associated with a possible indication of increased risk of ICC, albeit non-significant, which was consistent in the cohorts in North America and the UK. However, the sample size was limited, and the UK Biobank only assessed type of MHT for women who reported 'current' MHT use at time of the questionnaire.

Experimental evidence suggests that oestrogen, potentially mediated through interleukin-6 (IL-6) ${ }^{10}$ or vascular endothelial growth factor (VEGF), ${ }^{8}$ promotes cholangiocarcinogenesis, while selective oestrogen receptor modulators can inhibit growth. ${ }^{8-10}$ Cholangiocytes can express both oestrogen receptor (ER)- $\alpha$ and $-\beta$, whereas hepatocytes express only ER-a. ${ }^{42}$ In bile duct ligated rats, ER- $\beta$ increased 5-fold in cholangiocytes, whereas ER-a decreased in both cholangiocytes and hepatocytes. ${ }^{42}$ Thus, the increased risk of ICC associated with oestrogen-only MHT use is biologically plausible through modulation of cholangiocyte proliferation. ${ }^{43,44}$ While statistical power was still somewhat limited to examine this hypothesis, both the LCPP and the UK Biobank reported nearly identical effect estimates for the oestrogen-only MHT-ICC association.

In epidemiologic investigations of circulating sex steroid hormones and ICC risk, two studies have reported higher levels of circulating oestradiol in both men and women cholangiocarcinoma cases compared to controls. ${ }^{11,12}$ One of these studies was based in the LCPP and reported that a doubling of circulating oestrogen levels in women was associated with a $40 \%$ increased ICC risk. ${ }^{12}$ Neither study reported associations with circulating androgen levels.

Of the reproductive factors, which have been utilised as proxies of hormone status, parity is the most well studied in 
Table 1. Characteristics of female participants in the Liver Cancer Pooling Project and the UK Biobank.

\begin{tabular}{|c|c|c|c|c|}
\hline & \multicolumn{2}{|l|}{ Liver Cancer Pooling Project } & \multicolumn{2}{|l|}{ UK Biobank } \\
\hline$<50$ & $153,709(18.1)$ & $9(5.0)$ & $62,807(24.5)$ & $5(8.8)$ \\
\hline $50-59$ & $286,553(33.7)$ & $52(28.9)$ & 88,718 (34.6) & 19 (33.3) \\
\hline $60-69$ & $332,574(39.1)$ & 97 (53.9) & $103,704(40.5)$ & $31(54.4)$ \\
\hline \multicolumn{5}{|l|}{ Menopausal status } \\
\hline Pre-menopausal & $134,595(15.8)$ & $9(5.0)$ & $62,992(24.6)$ & $4(7.0)$ \\
\hline Post-menopausal & $706,218(83.0)$ & $171(95.0)$ & $152,752(59.6)$ & 41 (71.9) \\
\hline Missing & $10,164(1.2)$ & $0(0.0)$ & $40,540(15.8)$ & $12(21.1)$ \\
\hline \multicolumn{5}{|l|}{ Alcohol intake } \\
\hline \multicolumn{5}{|l|}{ Liver Cancer Pooling Project } \\
\hline Quartile 4: >13.54 g/day & $98,621(11.6)$ & $21(11.7)$ & & \\
\hline Missing & $41,145(4.8)$ & $9(5.0)$ & & \\
\hline \multicolumn{5}{|l|}{ UK Biobank } \\
\hline Never & & & $15,072(5.9)$ & $4(7.0)$ \\
\hline Current $(<16 \mathrm{~g} /$ day $)$ & & & $167,319(65.3)$ & $39(68.4)$ \\
\hline Current ( $\geq 16 \mathrm{~g} /$ day) & & & $62,762(24.5)$ & $10(17.5)$ \\
\hline Former & & & 9251 (3.6) & $4(7.0)$ \\
\hline Missing & & & $1,880(0.7)$ & $0(0.0)$ \\
\hline \multicolumn{5}{|l|}{ Smoking status } \\
\hline Never & $434,198(51.0)$ & $80(44.4)$ & $152,637(59.6)$ & $20(35.1)$ \\
\hline Former & $284,799(33.5)$ & $75(41.7)$ & $79,316(30.9)$ & $29(50.9)$ \\
\hline \multicolumn{5}{|l|}{ Diabetes } \\
\hline No & $792,844(93.2)$ & $159(88.3)$ & $247,484(96.6)$ & $56(98.3)$ \\
\hline Yes & $45,678(5.4)$ & $18(10.0)$ & $8800(3.4)$ & $1(1.7)$ \\
\hline Missing & $12,455(1.5)$ & $3(1.7)$ & $0(0.0)$ & $0(0.0)$ \\
\hline \multicolumn{5}{|l|}{ Race } \\
\hline White & $715,739(84.1)$ & $156(86.7)$ & & \\
\hline Black & $93,734(11.0)$ & $9(5.0)$ & & \\
\hline Asian/Pacific Islander & $11,297(1.3)$ & $4(2.2)$ & & \\
\hline American Indian/Alaskan Native & $2,032(0.2)$ & 00.0 & & \\
\hline Other & $19,336(2.3)$ & $7(3.9)$ & & \\
\hline Missing & $8,839(1.0)$ & $4(2.2)$ & & \\
\hline \multicolumn{5}{|l|}{ Education } \\
\hline High School or Less & $45,659(5.4)$ & $12(6.7)$ & & \\
\hline High School & $184,586(21.7)$ & $32(17.8)$ & $73,038(28.5)$ & $10(17.5)$ \\
\hline Some College/Vocational & $257,563(30.3)$ & $59(32.8)$ & & \\
\hline College Degree & $190,027(22.3)$ & $44(24.4)$ & $41,596(16.2)$ & $8(14.0)$ \\
\hline Graduate Degree & $135,288(15.9)$ & $25(13.9)$ & $94,233(36.8)$ & $18(31.6)$ \\
\hline None of the above & & & $42,439(16.6)$ & $20(35.1)$ \\
\hline Missing & $37,854(4.4)$ & $8(4.4)$ & $4978(1.9)$ & $1(1.8)$ \\
\hline
\end{tabular}


Table 2. Association between reproductive factors and intrahepatic cholangiocarcinoma in the Liver Cancer Pooling Project and the UK Biobank.

\begin{tabular}{|c|c|c|c|c|c|c|c|c|c|c|}
\hline $\begin{array}{l}\text { Reproductive } \\
\text { Factors }\end{array}$ & \multicolumn{4}{|c|}{ Liver Cancer Pooling Project } & \multicolumn{4}{|l|}{ UK Biobank } & \multicolumn{2}{|c|}{ Combined } \\
\hline$<12$ & 207,893 & 49 & & Referent & 39,215 & 4 & & Referent & & Referent \\
\hline $12-13$ & 366,443 & 72 & 0.73 & $0.50-1.07$ & 89,034 & 23 & 2.59 & $0.89-7.51$ & 0.84 & $0.59-1.20$ \\
\hline$p$ for trend & & & & 0.72 & & & & 0.36 & & \\
\hline \multicolumn{11}{|l|}{ Ever had children } \\
\hline No & 98,304 & 20 & & Referent & 40,205 & 6 & & Referent & & Referent \\
\hline Yes & 611,875 & 134 & 0.87 & $0.54-1.39$ & 169,121 & 38 & 1.14 & $0.47-2.73$ & 0.92 & $0.61-1.41$ \\
\hline Missing & 11,971 & 0 & & & 138 & 0 & & & & \\
\hline $3+$ & 345,531 & 83 & 0.82 & $0.50-1.35$ & 49,752 & 13 & 1.16 & $0.43-3.13$ & 0.88 & $0.56-1.37$ \\
\hline Missing & 15,133 & 1 & & & 0 & 0 & & & & \\
\hline$p$ for trend & & & & 0.97 & & & & 0.35 & & \\
\hline \multicolumn{11}{|c|}{ Age at first birth (parous women) } \\
\hline$<21$ & 105,544 & 19 & & Referent & 19,734 & 5 & & Referent & & Referent \\
\hline $21-24$ & 275,185 & 72 & 1.31 & $0.77-2.21$ & 40,407 & 8 & 0.88 & $0.28-2.73$ & 1.22 & $0.75-1.98$ \\
\hline $25-28$ & 147,059 & 25 & 0.74 & $0.39-1.39$ & 44,890 & 9 & 1.26 & $0.40-3.95$ & 0.84 & $0.48-1.47$ \\
\hline$\geq 29$ & 59,050 & 15 & 1.02 & $0.49-2.11$ & 35,669 & 9 & 1.87 & $0.57-6.16$ & 1.21 & $0.65-2.25$ \\
\hline Missing & 135,312 & 23 & & & 28,419 & 7 & & & & \\
\hline$p$ for trend & & & & 0.62 & & & & 0.90 & & \\
\hline $1-2.5$ years & 77,857 & 12 & 1.09 & $0.59-2.01$ & 17,999 & 3 & 0.92 & $0.25-3.45$ & 1.06 & $0.61-1.84$ \\
\hline $2.5-6$ years & 50,176 & 5 & 0.59 & $0.24-1.49$ & 22,069 & 7 & 2.00 & $0.72-5.51$ & 1.01 & $0.51-1.98$ \\
\hline $6-9$ years & 70,620 & 11 & 1.00 & $0.54-1.88$ & 22,277 & 3 & 0.94 & $0.25-3.59$ & 0.99 & $0.57-1.73$ \\
\hline $9+$ years & 61,781 & 17 & 1.71 & $1.01-2.89$ & 78,287 & 14 & 1.38 & $0.56-3.39$ & 1.62 & $1.03-2.55$ \\
\hline Missing & 10,235 & 0 & & & 22,696 & 6 & & & & \\
\hline$p$ for trend & & & & 0.14 & & & & 0.46 & & \\
\hline
\end{tabular}

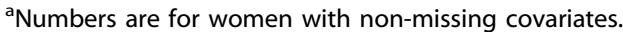

${ }^{b}$ Adjusted for age (continuous), alcohol (g/day: none, $\left.\leq 1.08,>1.08-3.58,>3.58-13.54,>13.54\right), \mathrm{BMl}\left(\mathrm{kg} / \mathrm{m}^{2}\right.$ : $\left.<25,25-29.9, \geq 30\right)$, diabetes (yes, no), race (white, other), smoking (never, former, current), parent cohort study, menopausal status (pre-, post-menopausal), and education (<high school, high school, some college/vocational, college, graduate degree).

${ }^{\mathrm{C}}$ Adjusted for age (continuous), alcohol (never, former, current light/occasional ( $\left.<16 \mathrm{~g} / \mathrm{day}\right)$, current heavy ( $\left.\geq 16 \mathrm{~g} / \mathrm{day}\right)$ ), BMl (kg/m²: $\left.<25,25-29.9, \geq 30\right)$ smoking (never, former, current), menopausal status (pre-, post-menopausal), and education (<secondary school, secondary school, college, graduate degree).

relation to primary liver cancer but there is significant heterogeneity in results. A recent meta-analysis reported a non-linear association, with a J-shaped relationship between parity and primary liver cancer. ${ }^{40}$ This restricted cubic spline model suggested that risk of primary liver cancer began to increase with more than five live births. Little to no association has been reported with age at menarche, age at first birth and age at menopause. However, two studies have reported oophorectomy is associated with an increased risk of HCC. ${ }^{39,45}$
Similarly, in two recent studies, medically recorded bilateral oophorectomy was associated with a $30-70 \%$ increased risk of non-alcoholic fatty liver disease. ${ }^{46,47}$ While the current study did not find an association with oophorectomy, there was an increased risk of ICC associated with hysterectomy. This could be due either to misclassified self-reported hysterectomy and oophorectomy status, ${ }^{48}$ whereby women that had an oophorectomy tend to misreport (i.e., report hysterectomy instead of oophorectomy), or to alterations in sex steroid hormones, 
Table 3. Associations between menopausal factors and menopausal hormone therapy (MHT) use among post-menopausal women and risk of intrahepatic cholangiocarcinoma in the Liver Cancer Pooling Project and the UK Biobank.

\begin{tabular}{|c|c|c|c|c|c|c|c|c|c|c|}
\hline Age at menopause & \multicolumn{4}{|c|}{ Liver Cancer Pooling Project } & \multicolumn{4}{|l|}{ UK Biobank } & \multicolumn{2}{|c|}{ Combined } \\
\hline$<45$ & 35,745 & 7 & 0.82 & $0.37-1.81$ & 11,273 & 14 & 1.21 & $0.38-3.84$ & 0.93 & $0.48-1.79$ \\
\hline $45-49$ & 89,227 & 15 & 0.68 & $0.38-1.23$ & 29,137 & 4 & 0.62 & $0.21-1.77$ & 0.67 & $0.40-1.11$ \\
\hline$p$ for trend & & & & 0.84 & & & & 0.59 & & \\
\hline \multicolumn{11}{|l|}{ Surgical menopause } \\
\hline $\begin{array}{l}\text { Bilateral } \\
\text { oophorectomy }\end{array}$ & 54,645 & 12 & 0.84 & $0.43-1.63$ & 687 & 0 & - & & - & \\
\hline Hysterectomy $^{d}$ & 100,694 & 36 & 2.25 & $1.38-3.65$ & 15,809 & 5 & 1.11 & $0.39-3.13$ & 1.98 & $1.27-3.09$ \\
\hline \multicolumn{11}{|c|}{ Menopausal hormone therapy (MHT) } \\
\hline Never & 259,833 & 65 & & Referent & 136,849 & 23 & & Referent & & Referent \\
\hline Ever use & 340,563 & 83 & 1.12 & $0.80-1.56$ & 72,057 & 21 & 1.05 & $0.56-1.96$ & 1.10 & $0.82-1.49$ \\
\hline Missing & 5,795 & 1 & & & 556 & 0 & & & & \\
\hline \multicolumn{11}{|l|}{ Timing of use } \\
\hline Never & 241,746 & 63 & & Referent & 136,849 & 23 & & Referent & & Referent \\
\hline Former & 81,684 & 22 & 0.92 & $0.56-1.50$ & 63,593 & 19 & 1.05 & $0.55-2.01$ & 0.97 & $0.65-1.43$ \\
\hline Current & 227,895 & 59 & 1.26 & $0.87-1.84$ & 8464 & 2 & 1.04 & $0.24-4.47$ & 1.25 & $0.87-1.78$ \\
\hline Missing & 54,866 & 5 & & & 556 & 0 & & & & \\
\hline \multicolumn{11}{|l|}{ Duration of use } \\
\hline \multicolumn{11}{|l|}{ MHT type $\mathrm{e}^{\mathrm{e}}$} \\
\hline None & 153,760 & 35 & & Referent & 136,849 & 23 & & Referent & & Referent \\
\hline Oestrogen only & 125,090 & 38 & 1.44 & $0.90-2.31$ & 2708 & 1 & 1.45 & 0.1910 .85 & 1.44 & $0.91-2.28$ \\
\hline Combination & 100,318 & 22 & 1.01 & $0.58-1.76$ & 5735 & 1 & 0.79 & $0.11-5.95$ & 0.99 & $0.58-1.69$ \\
\hline Other MHT & 15,982 & 1 & 0.34 & $0.05-2.54$ & & & & & & \\
\hline Missing & 196,844 & 44 & & & 64,149 & 19 & & & & \\
\hline \multicolumn{11}{|l|}{ MHT pill usage $e^{e}$} \\
\hline None & 87,966 & 24 & & Referent & 136,849 & 23 & & Referent & & Referent \\
\hline Used pills & 118,376 & 36 & 1.06 & $0.63-1.79$ & 6,501 & 2 & 1.34 & $0.31-5.76$ & 1.09 & $0.67-1.78$ \\
\hline Other MHT & 8,467 & 1 & 0.55 & $0.07-4.10$ & 1879 & 0 & - & & & \\
\hline Missing & 377,185 & 79 & & & 64,233 & 19 & & & & \\
\hline $\begin{array}{l}\text { a Numbers are for womer } \\
{ }^{\mathrm{b}} \text { Adjusted for age (contin } \\
\text { other), smoking (never, } \mathrm{f} \\
\text { college/vocational, colleg } \\
{ }^{\mathrm{c}} \text { Adjusted for age (contin } \\
\text { (never, former, current), } \mathrm{r} \\
{ }^{\mathrm{d}} \text { Reference group for oo, } \\
{ }^{\mathrm{e}} \text { Information on MHT typ }\end{array}$ & $\begin{array}{l}\text { with non-missing } \\
\text { uous), alcohol (g/c } \\
\text { rmer, current), pa } \\
\text { e, graduate degre } \\
\text { ous), alcohol (neve } \\
\text { lenopausal status } \\
\text { horectomy and hy } \\
\text { and pill usage o }\end{array}$ & $\begin{array}{l}\text { fariates. } \\
\text { none, } \leq 1.08,>1 \\
\text { cohort study, } n \\
\text { rmer, current lic } \\
\text { rectomy is fema } \\
\text { available for cur }\end{array}$ & $\begin{array}{l}\text { menop } \\
\text { ght/oc } \\
\text { usal), c } \\
\text { ales wh } \\
\text { rrent N }\end{array}$ & $\begin{array}{l}\text { ausal status } \\
\text { and educatio }(<16 \\
\text { o had natur } \\
\text { IHT users at }\end{array}$ & $\begin{array}{l}.54,>13.54), \mathrm{BMI} \\
\text { (pre-, post-meno } \\
\mathrm{g} / \text { day), current } \mathrm{h} \\
\text { on }(<\text { secondary sc } \\
\text { al menopause ag } \\
\text { baseline in the } U\end{array}$ & $\begin{array}{l}\text { y ( } \geq 16 \mathrm{~g} / \text { day })), \mathrm{B} \\
\mathrm{ol} \text {, secondary sch } \\
\text { between } 50 \text { anc } \\
\text { Biobank. }\end{array}$ & $\begin{array}{l}\text { MI (kg/ } \\
\text { hool, c } \\
\text { d } 54 \text { ye }\end{array}$ & $\begin{array}{l}\text { diabetes (ye } \\
\text { high school, }, \\
\mathrm{m}^{2}:<25,25-2 \\
\text { ollege, gradua } \\
\text { ars old. }\end{array}$ & $\begin{array}{l}\text { s, no), } \\
\text { high sc } \\
9.9, \geq 3 \\
\text { ate deg }\end{array}$ & $\begin{array}{l}\text { ace (white, } \\
\text { hool, some } \\
\text { 0), smoking } \\
\text { ree). }\end{array}$ \\
\hline
\end{tabular}


particularly decreased androgen levels, in hysterectomised women. ${ }^{49}$ Additionally, women undergoing hysterectomy may be more likely to begin taking MHT. ${ }^{50}$ We also report that MHT use, in particular oestrogen-only MHT use, is more common among women who report hysterectomy than in those who report natural menopause. However, the LCPP does not have information on age at hysterectomy. In the UK Biobank, only $26 \%$ of participants started taking MHT after hysterectomy $(7 \%$ within 1-year post-hysterectomy); thus, MHT initiation is not strongly related to hysterectomy. Further, adjustment for MHT use did not substantially change the hysterectomy-ICC association. Alternatively, hysterectomy, which has been associated with weight gain and diabetes, may have indirect effects on ICC risk. ${ }^{51,52}$ In a recent meta-analysis, we reported that excess adiposity and diabetes were both associated with a $50 \%$ increased ICC risk. ${ }^{53}$ Thus, hysterectomy could be leading to weight gain or development of diabetes in women that places them at higher ICC risk.

The current report is the first study focused specifically on reproductive factors and ICC. The large population of over 1.1 million women available from combining the LCPP and the UK Biobank allowed for investigation of reproductive factors and exogenous hormonal exposures in relation to ICC risk, which is a rare tumour with incidence rates typically $1.0 / 100,000$ or less. Further, as the baseline enrolment for cohorts in the LCPP was 1980-1998 and in the UK Biobank was 2006-2010, the associations reported in both studies suggest that secular trends did not have influential effects. This study included a wide geographic representation from North America and the UK. Additionally, the prospective design minimises recall bias. In addition, sensitivity analyses that excluded ICCs that developed in the first two years of follow-up supported the results of the main analysis.

Limitations include exposure capture, risk factor information, and generalisability. All exposures in the included cohorts were self-reported. Thus, some of the exposures, for example oophorectomy, may not be reported accurately compared to medical report. However, the majority of studies to date have relied on self-reported data. In particular, for oral contraceptive use, there are not currently good resources with prescription information and sufficient follow-up for any liver cancer outcome. Formulations of oral contraceptives have changed over time, which makes examining and definitively addressing the association between oral contraceptive use and ICC challenging. Additionally, there was no information on specific MHT formulations, and for the UK Biobank, type of MHT used was only available for women currently reporting MHT use at the time of questionnaire administration. As serum or plasma samples were only available for a small number of ICC cases, we were unable to include HBV or HCV as potential covariates. However, the prevalence of $\mathrm{HBV}$ and $\mathrm{HCV}$ in the general population of women in the US and UK is exceedingly low $(\leq 1 \%) .{ }^{54-56}$ Further, the UK Biobank is in the process of testing all participants for viral factors but the data are not yet publicly available. As these cohorts were established to examine all cancer types, and not specifically liver cancer, there is no information on pre-existing liver disease among the participants in the LCPP. Models are adjusted for diabetes, but diabetes type (1 or 2 ) is not captured in the majority of LCPP cohorts. However, type 2 diabetes accounts for $95 \%$ of diabetes diagnoses. ${ }^{57}$ As this is an older population, diabetes is utilised as a proxy of type 2 diabetes. Finally, this is a population of primarily white post-menopausal women. Thus, the generalisability of these results to other racial/ ethnic groups may not be assumed.

In summary, we report that long-term oral contraceptive use and hysterectomy are associated with an increased risk of ICC. Other reproductive factors were unrelated to risk. While intriguing, replication of these findings is warranted, ideally in populations with medical record data to avoid potential misclassification of exposures.

\section{ACKNOWLEDGEMENTS}

For the Black Women's Health Study, pathology data were obtained from several of the following state cancer registries $(A Z, C A, C O, C T, D E, D C, F L, G A, I L, I N, K Y, L A, M D$, MA, MI, NJ, NY, NC, OK, PA, SC, TN, TX, VA), and results reported do not necessarily represent their views. For the Nurses' Health Study and the Health Professionals Follow-up Study, we would like to thank the following state cancer registries for their help: AL, AZ, AR, CA, CO, CT, DE, FL, GA, ID, IL, IN, IA, KY, LA, ME, MD, MA, MI, NE, NH, NJ, NY, NC, ND, OH, OK, OR, PA, RI, SC, TN, TX, VA, WA, WY. We assume full responsibility for analyses and interpretation of these data. For NIH-AARP, the acknowledgement can be found at the following website: https://dietandhealth. cancer.gov/acknowledgement.html. For the Women's Health Initiative, the full list of investigators that have contributed can be found on the following website: https:// www.whi.org/researchers/Documents\%20\%20Write\%20a\%20Paper/WHI\%

20Investigator\%20Long\%20List.pdf. The American Cancer Society funds the creation, maintenance, and updating of the Cancer Prevention Study-II cohort. The authors express sincere appreciation to all Cancer Prevention Study-II participants, and to each member of the study and biospecimen management group. We would like to acknowledge the contribution to this study from central cancer registries supported through the Centers for Disease Control and Prevention's National Program of Cancer Registries and cancer registries supported by the National Cancer Institute's Surveillance Epidemiology and End Results Program.

\section{AUTHOR CONTRIBUTIONS}

Study concept and design, acquisition of data, analysis and interpretation of data, drafting of the paper, critical revision of the paper for important intellectual content, and statistical analysis: J.L.P. and Ú.C.M.; interpretation of data and critical revision of the paper for important intellectual content: B.I.G.; design and collection data from individual cohort studies, design of the consortium, interpretation of data, and critical revision of the paper for important intellectual content: X.Z., A.Z-J., J.W-W., T.G.S., R.S., H.D.S., C.S., L.R., T.E.R., K.R., M.P.P., J.N.P., J.R.P., Y.L., M.S.L., L.M.L., I-M.L., J.K., C.M.K., V.A.K., J.N.H., E.G., J.M.G., S.M.G., N.D.F., A.A.F., D.Q.C., Y.C., A.T.C., J.E.B., L.E.B, J.W.B., C.R.C., P.T.C.; concept and design of the consortium, collection of data for the consortium, analysis and interpretation of data, and critical revision of the paper for important intellectual content: K.A.M. All authors approved the final draft submitted.

\section{ADDITIONAL INFORMATION}

Ethical approval and consent to participate In the LCPP, the individual cohorts were approved by the institutional review boards of the participating institutions; the LCPP was approved by the NIH Office of Human Subjects Research. The UK Biobank was approved by the North West Multi-Centre Research Ethics Committee. All participants provided written informed consent, and the study was performed in accordance with the Declaration of Helsinki.

Data availability Data can be obtained for legitimate research purposes. Access to LCPP data can be provided by submitting a request to Katherine McGlynn (mcglynnk@mail.nih.gov) or Peter Campbell (peter.campbell@cancer.org). UK Biobank data can be provided by submitting an application to the UK Biobank (https:// www.ukbiobank.ac.uk/).

\section{Competing interests The authors declare no competing interests.}

Funding infromation Access to the UK Biobank was funded by a Cancer Research UK Population Research Postdoctoral Fellowship (Ú.C.M.). NIH Intramural Research Program, National Cancer Institute (J.L.P., A.A.F., L.E.B.F., J.N.H., C.M.K., N.D.F., B.I.G., J.K., L.M.L., M.S.L., M.P.P., C.S., R.S., K.A.M.). National Institutes of Health grants CA047988 (I. L., J.E.B.), CA182913 (I.L., J.E.B.), HL043851 (I.L., J.E.B.), HL080467 (I.L., J.E.B.), HL099355 (I.L., J.E.B.), K07 CA188126 (X.Z.), DK098311 (A.T.C.), CA186107 (A.T.C.), CA87969 (A.T. C.), CA167552 (A.T.C.), P30 CA016087 (A.Z-J.), P30 ES000260 (A.Z-J.), UM1 CA164974 (L Rosenberg, JR Palmer), R01 CA058420 (L.R., J.R.P.), and R01 CA39742 (K.R., J.N.P.). American Cancer Society Research Scholar Grant RSG NEC-130476 (X.Z.). The WHI program (J.W-W., T.E.R., Y.L., J.W.B.) is funded by the National Institutes of Health contracts HHSN268201600018C, HHSN268201600001C, HHSN268201600002C, HHSN268201600003C and HHSN268201600004C. The HPFS and NHS programs (X. Z.) were support by the National Cancer Institute, National Institutes of Health grant numbers UM1CA186107, P50CA127003, P01CA87969 and UM1CA167552.

Supplementary information is available for this paper at https://doi.org/10.1038/ s41416-020-0835-5. 
Publisher's note Springer Nature remains neutral with regard to jurisdictional claims in published maps and institutional affiliations.

\section{REFERENCES}

1. Saha, S. K., Zhu, A. X., Fuchs, C. S. \& Brooks, G. A. Forty-year trends in cholangiocarcinoma Incidence in the U.S.: intrahepatic disease on the rise. Oncologist 21, 594-599 (2016)

2. Surveillance, Epidemiology, and End Results (SEER) Program (https://www.seer. cancer.gov) SEER*Stat Database: National Program of Cancer Registries (NPCR) and SEER Incidence - U.S. Cancer Statistics Public Use Database, Nov 2018 Sub (2001-2016), National Cancer Institute, DCCPS, Surveillance Research Program, released April 2019, based on the November 2018 submission.

3. Altekruse, S. F., Devesa, S. S., Dickie, L. A., McGlynn, K. A. \& Kleiner, D. E. Histological classification of liver and intrahepatic bile duct cancers in SEER registries. J. registry Manag. 38, 201-205 (2011).

4. Alvaro, D., Alpini, G., Onori, P., Franchitto, A., Glaser, S. S., Le Sage, G. et al. Alfa and beta estrogen receptors and the biliary tree. Mol. Cell Endocrinol. 193, 105-108 (2002).

5. Alvaro, D., Alpini, G., Onori, P., Franchitto, A., Mancino, M. G., Glaser, S. et al. Estrogen Regulation of Cholangiocyte Proliferation. Madame Curie Bioscience Database. (Landes Bioscience, Austin, 2000).

6. Alvaro, D., Barbaro, B., Franchitto, A., Onori, P., Glaser, S. S., Alpini, G. et al. Estrogens and insulin-like growth factor 1 modulate neoplastic cell growth in human cholangiocarcinoma. Am. J. Pathol. 169, 877-888 (2006).

7. London W. T., Petrick J. L., McGlynn K. A. Liver Cancer. in Schottenfeld and Fraumeni cancer epidemiology and prevention, 4th edn (eds Thun M. J., Linet M. S. Cerhan J. R. \& Haiman C., Schottenfeld D.) pp xix, 1308 pages. (Oxford University Press: New York, 2018) pp xix, 1308 pages.

8. Mancino, A., Mancino, M. G., Glaser, S. S., Alpini, G., Bolognese, A., Izzo, L. et al. Estrogens stimulate the proliferation of human cholangiocarcinoma by inducing the expression and secretion of vascular endothelial growth factor. Dig. Liver Dis. 41, 156-163 (2009)

9. Sampson, L. K., Vickers, S. M., Ying, W. \& Phillips, J. O. Tamoxifen-mediated growth inhibition of human cholangiocarcinoma. Cancer Res. 57, 1743-1749 (1997).

10. Isse, K., Specht, S. M., Lunz, J. G. 3rd, Kang, L. I., Mizuguchi, Y. \& Demetris, A. J. Estrogen stimulates female biliary epithelial cell interleukin- 6 expression in mice and humans. Hepatology 51, 869-880 (2010).

11. Hunsawong, T., Singsuksawat, E., In-chon, N., Chawengrattanachot, W., Thuwajit, C., Sripa, B. et al. Estrogen is increased in male cholangiocarcinoma patients' serum and stimulates invasion in cholangiocarcinoma cell lines in vitro. J. Cancer Res Clin. Oncol. 138, 1311-1320 (2012).

12. Petrick J. L., Florio A. A., Zhang X., Zeleniuch-Jacquotte A., Wactawski-Wende J Van Den Eeden S. K. et al. Associations between Prediagnostic concentrations of circulating sex steroid hormones and liver cancer among post-menopausal women. Hepatology. https://doi.org/10.1002/hep.31057 (2019).

13. McGlynn K. A., Sahasrabuddhe V. V., Campbell P. T., Graubard B. I., Chen J. Schwartz L. M. et al. Reproductive factors, exogenous hormone use and risk of liver cancer among U.S. women: results from the Liver Cancer Pooling Project. Br J Cancer. 112, 1266-1272 (2015).

14. Simin, J., Tamimi, R., Lagergren, J., Adami, H. O. \& Brusselaers, N. Menopausal hormone therapy and cancer risk: an overestimated risk? Eur. J. Cancer 84, 60-68 (2017).

15. Schatzkin, A., Subar, A. F., Thompson, F. E., Harlan, L. C., Tangrea, J., Hollenbeck, A. R. et al. Design and serendipity in establishing a large cohort with wide dietary intake distributions: the National Institutes of Health-American Association of Retired Persons Diet and Health Study. Am. J. Epidemiol. 154, 1119-1125 (2001).

16. Alavanja, M. C., Sandler, D. P., McMaster, S. B., Zahm, S. H., McDonnell, C. J., Lynch C. F. et al. The agricultural health study. Environ. Health Perspect. 104, 362-369 (1996).

17. Flood, A., Velie, E. M., Chaterjee, N., Subar, A. F., Thompson, F. E., Lacey, J. V. Jr. et al. Fruit and vegetable intakes and the risk of colorectal cancer in the Breast Cancer Detection Demonstration Project follow-up cohort. Am. J. Clin. Nutr. 75, 936-943 (2002)

18. Kramer, B. S., Gohagan, J., Prorok, P. C. \& Smart, C. A National Cancer Institute sponsored screening trial for prostatic, lung, colorectal, and ovarian cancers. Cancer 71(Suppl. 2), 589-593 (1993)

19. Rexrode, K. M., Lee, I. M., Cook, N. R., Hennekens, C. H. \& Buring, J. E. Baseline characteristics of participants in the Women's Health Study. J. women's health Gend-based Med. 9, 19-27 (2000).

20. Toniolo, P. G., Pasternack, B. S., Shore, R. E., Sonnenschein, E., Koenig, K. L., Rosenberg, $C$. et al. Endogenous hormones and breast cancer: a prospective cohort study. Breast Cancer Res. Treat. 18(Suppl. 1), S23-S26 (1991).
21. Calle, E. E., Rodriguez, C., Jacobs, E. J., Almon, M. L., Chao, A., McCullough, M. L. et al. The American Cancer Society Cancer Prevention Study II Nutrition Cohort: rationale, study design, and baseline characteristics. Cancer 94, 2490-2501 (2002).

22. Munger, R. G., Folsom, A. R., Kushi, L. H., Kaye, S. A. \& Sellers, T. A. Dietary assessment of older lowa women with a food frequency questionnaire: nutrient intake, reproducibility, and comparison with 24-hour dietary recall interviews. Am. J. Epidemiol. 136, 192-200 (1992).

23. Rosenberg, L., Adams-Campbell, L. \& Palmer, J. R. The Black Women's Health Study: a follow-up study for causes and preventions of illness. J. Am. Med. Women's Assoc. 50, 56-58 (1995).

24. Anderson, G. L., Manson, J., Wallace, R., Lund, B., Hall, D., Davis, S. et al. Implementation of the Women's Health Initiative study design. Ann. Epidemiol. 13 (Suppl. 9), S5-S17 (2003).

25. Belanger, C. F., Hennekens, C. H., Rosner, B. \& Speizer, F. E. The nurses' health study. Am. J. Nurs. 78, 1039-1040 (1978).

26. Rohan, T. E., Soskolne, C. L., Carroll, K. K. \& Kreiger, N. The Canadian Study of Diet, Lifestyle, and Health: design and characteristics of a new cohort study of cancer risk. Cancer Detect Prev. 31, 12-17 (2007).

27. Steering Committee of the PHS Research Group. Final report on the aspirin component of the ongoing Physicians' Health Study. N. Engl. J. Med. 321 129-135 (1989).

28. Grobbee, D. E., Rimm, E. B., Giovannucci, E., Colditz, G., Stampfer, M. \& Willett, W. Coffee, caffeine, and cardiovascular disease in men. N. Engl. J. Med. 323 1026-1032 (1990).

29. Boice, J. D. Jr., Mandel, J. S., Doody, M. M., Yoder, R. C. \& McGowan, R. A health survey of radiologic technologists. Cancer 69, 586-598 (1992).

30. Sudlow, C., Gallacher, J., Allen, N., Beral, V., Burton, P., Danesh, J. et al. UK biobank: an open access resource for identifying the causes of a wide range of complex diseases of middle and old age. PLoS Med. 12, e1001779 (2015).

31. Catsburg, C., Kirsh, V. A., Soskolne, C. L., Kreiger, N., Bruce, E., Ho, T. et al. Associations between anthropometric characteristics, physical activity, and breast cancer risk in a Canadian cohort. Breast cancer Res. Treat. 145, 545-552 (2014).

32. The SURVEYPHREG Procedure. in SAS/STAT ${ }^{\circledR} 14.3$ User's Guide. (SAS Institute Inc., Cary, 2017).

33. Rothman, K. J., Greenland, S. \& Lash, T. L. Modern epidemiology. Wolters Kluwer Health/. 3rd edn. (Lippincott Williams \& Wilkins, Philadelphia, 2008).

34. McGlynn, K. A., Petrick, J. L. \& London, W. T. Global epidemiology of hepatocellular carcinoma: an emphasis on demographic and regional variability. Clin. Liver Dis. 19, 223-238 (2015).

35. Van Dyke, A. L., Shiels, M. S., Jones, G. S., Pfeiffer, R. M., Petrick, J. L., BeebeDimmer, J. L. et al. Biliary tract cancer incidence and trends in the United States by demographic group, 1999-2013. Cancer 125, 1489-1498 (2019).

36. IARC. Hormonal contraception and post-menopausal hormonal therapy 72 (IARC Press, Lyon, 1999).

37. An, N. Oral contraceptives use and liver cancer risk: a dose-response meta-analysis of observational studies. Medicine 94, e1619 (2015).

38. IARC. Combined Estrogen-Progesterone Contraceptives 100A. (IARCPress, Lyon, 2018).

39. McGlynn, K. A., Sahasrabuddhe, V. V., Campbell, P. T., Graubard, B. I., Chen, J., Schwartz, L. M. et al. Reproductive factors, exogenous hormone use and risk of hepatocellular carcinoma among US women: results from the Liver Cancer Pooling Project. Br. J. Cancer 112, 1266-1272 (2015).

40. Zhong, G. C., Liu, Y., Chen, N., Hao, F. B., Wang, K., Cheng, J. H. et al. Reproductive factors, menopausal hormone therapies and primary liver cancer risk: a systematic review and dose-response meta-analysis of observational studies. Hum. Reprod. Update 23, 126-138 (2016).

41. McGlynn, K. A., Hagberg, K., Chen, J., Braunlin, M., Graubard, B. I., Suneja, N. et al. Menopausal hormone therapy use and risk of primary liver cancer in the clinical practice research datalink. Int J. Cancer 138, 2146-2153 (2016).

42. Alvaro, D., Alpini, G., Onori, P., Perego, L., Svegliata Baroni, G., Franchitto, A. et al. Estrogens stimulate proliferation of intrahepatic biliary epithelium in rats. Gastroenterology 119, 1681-1691 (2000).

43. Mancinelli, R., Onori, P., Demorrow, S., Francis, H., Glaser, S., Franchitto, A. et al. Role of sex hormones in the modulation of cholangiocyte function. World $\mathrm{J}$. Gastrointest. Pathophysiol. 1, 50-62 (2010).

44. Alvaro, D., Mancino, M. G., Onori, P., Franchitto, A., Alpini, G., Francis, H. et al. Estrogens and the pathophysiology of the biliary tree. World J. Gastroenterol. 12, 3537-3545 (2006).

45. Yu, M. W., Chang, H. C., Chang, S. C., Liaw, Y. F., Lin, S. M., Liu, C. J. et al. Role of reproductive factors in hepatocellular carcinoma: Impact on hepatitis B- and Crelated risk. Hepatology 38, 1393-1400 (2003).

46. Matsuo, K., Gualtieri, M. R., Cahoon, S. S., Jung, C. E., Paulson, R. J., Shoupe, D. et al. Surgical menopause and increased risk of nonalcoholic fatty liver disease in endometrial cancer. Menopause 23, 189-196 (2016). 
Exogenous hormone use, reproductive factors and risk of intrahepatic...

$J \mathrm{~L}$ Petrick et al.

324

47. Florio A. A., Graubard B. I., Yang B., Thistle J. E., Bradley M. C., McGlynn K. A. et al. Oophorectomy and risk of non-alcoholic fatty liver disease and primary liver cancer in the Clinical Practice Research Datalink. Eur. J. Epidemiol. https://doi.org/ 10.1007/s10654-019-00526-1 (2019).

48. Phipps, A. I. \& Buist, D. S. Validation of self-reported history of hysterectomy and oophorectomy among women in an integrated group practice setting. Menopause 16, 576-581 (2009).

49. Laughlin, G. A., Barrett-Connor, E., Kritz-Silverstein, D. \& von Muhlen, D. Hysterectomy, oophorectomy, and endogenous sex hormone levels in older women: the Rancho Bernardo Study. J. Clin. Endocrinol. Metab. 85, 645-651 (2000).

50. Haney, A. F. \& Wild, R. A. Options for hormone therapy in women who have had a hysterectomy. Menopause 14, 592-597 (2007).

51. Moorman, P. G., Schildkraut, J. M., Iversen, E. S., Myers, E. R., Gradison, M., WarrenWhite, N. et al. A prospective study of weight gain after premenopausal hysterectomy. J. Women's Health (Larchmt.) 18, 699-708 (2009). e-pub ahead of print 2009/05/19.

52. Appiah, D., Winters, S. J. \& Hornung, C. A. Bilateral oophorectomy and the risk of incident diabetes in postmenopausal women. Diabetes Care 37, 725-733 (2014).

53. Petrick, J. L., Thistle, J. E., Zeleniuch-Jacquotte, A., Zhang, X., Wactawski-Wende, J., Van Dyke, A. L. et al. Body mass index, diabetes and intrahepatic cholangiocarcinoma risk: The Liver Cancer Pooling Project and Meta-analysis. Am. J. Gastroenterol. 113, 1494-1505 (2018).

54. Balogun, M. A., Ramsay, M. E., Hesketh, L. M., Andrews, N., Osborne, K. P., Gay, N. J. et al. The prevalence of hepatitis C in England and Wales. J. Infect. 45, 219-226 (2002).

55. Roberts, H., Kruszon-Moran, D., Ly, K. N., Hughes, E., Iqbal, K., Jiles, R. B. et al. Prevalence of chronic hepatitis B virus (HBV) infection in U.S. households:
National Health and Nutrition Examination Survey (NHANES), 1988-2012. Hepatology 63, 388-397 (2016).

56. Alter M. J., Kruszon-Moran D., Nainan O. V., McQuillan G. M., Gao F. X., Moyer L. A. et al. The prevalence of hepatitis C virus infection in the United States, 1988 through 1994. N. Engl. J. Med. 341, 556-562 (1999).

57. Centers for Disease Control and Prevention. National Diabetes Statistics Report, 2017. (Centers for Disease Control and Prevention, U.S. Dept of Health and Human Services, Atlanta, 2017).

(i) Open Access This article is licensed under a Creative Commons Attribution 4.0 International License, which permits use, sharing, adaptation, distribution and reproduction in any medium or format, as long as you give appropriate credit to the original author(s) and the source, provide a link to the Creative Commons license, and indicate if changes were made. The images or other third party material in this article are included in the article's Creative Commons license, unless indicated otherwise in a credit line to the material. If material is not included in the article's Creative Commons license and your intended use is not permitted by statutory regulation or exceeds the permitted use, you will need to obtain permission directly from the copyright holder. To view a copy of this license, visit http://creativecommons. org/licenses/by/4.0/.

This is a U.S. government work and not under copyright protection in the U.S.; foreign copyright protection may apply 2020 